\title{
Study on recovery of copper and zinc from cyanide lean solution in a smelting company
}

\author{
Qin Guanglin $^{1 *}$, Li Guangsheng ${ }^{1}$, Zhu Xingfu ${ }^{1}$, Gao Tengyue ${ }^{1}$, Chen Yanbo ${ }^{1}$, Ji Qiang ${ }^{1}$, Yu Congquan ${ }^{1}$, Lu Zhongbo ${ }^{1}$, Zhang \\ Juntong $^{1}$, Xu Chao ${ }^{1}$, Cai Mingming ${ }^{1}$ \\ ${ }^{1}$ Dressing and Smelting Laboratory Branch, Shandong Gold Mining Technology Co.,Ltd., Laizhou, Shandong ,China
}

\begin{abstract}
Abatract. In the process of cyanidation of gold concentrate from a smelting company, the content of copper and zinc in the liquid gradually increased. In production, acidizing process is used to treat the lean solution from high copper concentrate, and mixed products containing copper, zinc and other metals are produced. In this paper, the $\mathrm{pH}$ value of zinc precipitation is 6.0 and the $\mathrm{pH}$ value of copper precipitation is 3.0 through theoretical calculation and experiment. The separation of copper and zinc in the lean solution is realized successfully. The zinc product with grade of $42.97 \%$ and the copper product with grade of $58.33 \%$ are produced.
\end{abstract}

\section{Introduction}

In the production process of a smelting company, the incoming gold concentrate enters the pre-leaching flotation process after grinding. In flotation, the gold concentrate is divided into high copper concentrate, high sulfur concentrate and low sulfur concentrate. After thickening and filtering, the three products respectively enter the corresponding cyanidation leaching system. The leaching solution is replaced by zinc powder, and the resulting lean solution returns to the cyanidation system. In the process of leaching, the copper and zinc in the lean liquor increase gradually. In the production, the lean liquor produced from high copper concentrate is treated by acidification to produce mixed products containing copper, zinc and other metals.

\section{Brief introduction of the process}

When copper and zinc are recovered from cyanide containing liquid respectively, two kinds of high-grade sulfide products can be produced. In the precipitation process, the main equilibrium reactions mainly include: the formation of $\mathrm{HCN}$ and the dissociation of $\mathrm{H}_{2} \mathrm{~S}$, the sulfide precipitation of copper and zinc, the dissociation of cyanide containing ligands and the formation of precipitates $^{[1-2]}$.

During the reaction, the precipitation reaction of copper and zinc is as follows:

$$
\begin{gathered}
\mathrm{CN}^{-}+\mathrm{H}^{+} \rightarrow \mathrm{HCN} \\
2 \mathrm{Cu}(\mathrm{CN})_{4}{ }^{3-}+8 \mathrm{H}^{+}+\mathrm{S}^{2-} \rightarrow \mathrm{Cu}_{2} \mathrm{~S} \downarrow+8 \mathrm{HCN} \\
\mathrm{Zn}(\mathrm{CN})_{4}{ }^{2-}+\mathrm{S}^{2-} \rightarrow \mathrm{ZnS} \downarrow+4 \mathrm{CN}^{-}
\end{gathered}
$$

It can be seen from Formula (1)- (3) that in the reaction process, metal (complex) ions and sulfur ions can form metal sulfide precipitation under different conditions, and release hydrogen cyanide and free cyanide ${ }^{[3-4]}$.

\section{Theoretical calculation}

\subsection{Related parameters}

Since there are many kinds of complex forms containing cyanide in copper, there is a complex equilibrium relationship between them. In this calculation process, it is considered that copper cyanide complex mainly exists in the form of $\mathrm{Cu}(\mathrm{CN})_{4}{ }^{3-}$. Zinc sulfide exists in two forms, one of which is $\alpha-\mathrm{ZnS}$. The solubility product of $\alpha-\mathrm{ZnS}$ is easier to form in theory. The iron ions in the solution exist in the form of $\mathrm{Fe}(\mathrm{CN})_{6}{ }^{4-}$.

The theoretical constant of $25^{\circ} \mathrm{C}$ is used in the calculation process, and the activity value is approximately replaced by the concentration value. The specific data are shown in Table 1.

Table 1 The constants used in the calculation process

\begin{tabular}{|c|c||c|c|}
\hline Dissociation Constant & Number & $\begin{array}{c}\text { Solubility } \\
\text { Product }\end{array}$ & Number \\
\hline $\mathrm{HCN}^{2} \mathrm{H}^{+}+\mathrm{CN}^{-}$ & $6.2 \times 10^{-10}$ & $\mathrm{Cu}_{2} \mathrm{~S}$ & $2.5 \times 10^{-48}$ \\
\hline $\mathrm{H}_{2} \mathrm{~S}=\mathrm{H}^{+}+\mathrm{HS}^{-}$ & $1.3 \times 10^{-7}$ & $\mathrm{CuS}$ & $6.3 \times 10^{-36}$ \\
\hline $\mathrm{H}_{2} \mathrm{~S}=\mathrm{H}^{+}+\mathrm{S}^{2-}$ & $7.1 \times 10^{-15}$ & $\alpha-\mathrm{ZnS}$ & $1.6 \times 10^{-24}$ \\
\hline $\begin{array}{c}\text { Complex stability } \\
\text { constant }\end{array}$ & Number & $\mathrm{CuSCN}$ & $4.8 \times 10^{-15}$ \\
\hline $\mathrm{Cu}(\mathrm{CN})_{4}^{3-}$ & $5.0 \times 10^{-28}$ & $\mathrm{Cu}_{2}\left[\mathrm{Fe}(\mathrm{CN})_{6}\right]$ & $1.3 \times 10^{-16}$ \\
\hline $\mathrm{Zn}(\mathrm{CN})_{4}^{2-}$ & $2.0 \times 10^{-17}$ & $\mathrm{Zn}_{2}\left[\mathrm{Fe}(\mathrm{CN})_{6}\right]$ & $4.0 \times 10^{-16}$ \\
\hline
\end{tabular}




\subsection{Calculation of $\mathrm{pH}$ value in precipitation process}

\subsection{1 pH calculation of zinc precipitation}

In the lean solution, $\mathrm{Zn}(\mathrm{CN})_{4}{ }^{2-}$ is the main zinc in the liquid. It can be seen from table 1 that the complex stability constant is $2.0 \times 10^{-17}$. When the concentration of zinc ion is $0.008 \mathrm{~mol} \cdot \mathrm{L}^{-1}$ in the solution, the concentration of cyanide ion is $1.51 \times 10^{-4} \mathrm{~mol} \cdot \mathrm{L}^{-1}$, the concentration of cyanide ion is $6.03 \times 10^{-4} \mathrm{~mol} \cdot \mathrm{L}^{-1}$. The weak acid dissociation constant of hydrogen cyanide is $6.2 \times 10^{-10}$, When the $\mathrm{pH}$ value of the solution is less than 5.99 , the dissociation reaction of $\mathrm{Zn}(\mathrm{CN})_{4}{ }^{2-}$ proceeds to the right, generating hydrogen cyanide gas and $\mathrm{ZnS}$ under the action of sulfur ion.

The reaction of zinc cyanogen complex in acid system is calculated as follows:

$$
\mathrm{Zn}(\mathrm{CN}){ }^{2-} \rightleftharpoons \mathrm{Zn}^{2+}+4 \mathrm{CN}^{-} \quad \mathrm{K}_{\mathrm{d}}=2.0 \times 10^{-17}
$$

In the solution of $0.008 \mathrm{~mol} \cdot \mathrm{L}-1$, it can be seen from the calculation that:

$$
\begin{gathered}
\mathrm{C}\left(\mathrm{Zn}^{2+}\right)=1.51 \times 10^{-4} \mathrm{~mol} \cdot \mathrm{L}^{-1} \\
\mathrm{C}\left(\mathrm{CN}^{-}\right)=6.03 \times 10^{-4} \mathrm{~mol} \cdot \mathrm{L}^{-1} \\
\mathrm{HCN} \rightleftharpoons \mathrm{H}^{+}+\mathrm{CN}^{-} \quad \mathrm{K}_{\mathrm{a}}=6.2 \times 10^{-10}
\end{gathered}
$$

When $\mathrm{C}\left(\mathrm{H}^{+}\right) \cdot \mathrm{C}\left(\mathrm{CN}^{-}\right)=\mathrm{K}_{\mathrm{a}}, \mathrm{HCN}$ gas overflows from the solution, the dissociation of zinc cyanide complex proceeds to the right, and $\mathrm{Zn}^{2+}$ in the solution increases gradually ${ }^{[5-6]}$. From this, It can be calculated that $\mathrm{C}\left(\mathrm{H}^{+}\right)$ $=1.03 \times 10^{-6} \mathrm{~mol} \cdot \mathrm{L}^{-1}$, the $\mathrm{pH}$ is 5.99 .

It should be noted that through the above calculation, the concentration of $\mathrm{Zn}^{2+}$ in the test solution is $1.51 \times 4$ $\mathrm{mol} \cdot \mathrm{L}^{-1}$, adding theoretical amount of $\mathrm{Na}_{2} \mathrm{~S}$, the concentration of sulfur ion in the solution is 8 . $46 \times 10^{-6} \mathrm{~mol} \cdot \mathrm{L}^{-1}$. Through the following calculation:

$$
\mathrm{C}\left(\mathrm{Zn}^{2+}\right) \cdot \mathrm{C}\left(\mathrm{S}^{2-}\right)=1.28 \times 10^{-9}>\mathrm{K}_{\mathrm{sp}(\mathrm{ZnS})}=1.6 \times 10^{-24}(8)
$$

Therefore, $\mathrm{ZnS}$ precipitation can also be produced by directly adding sodium sulfide into high copper lean solution. Since copper precipitation needs to be carried out under lower $\mathrm{pH}$ value, in order to accelerate the formation of $\mathrm{ZnS}$ precipitation, sulfuric acid is used to adjust the $\mathrm{pH}$ value of liquid in this precipitation stage.

\subsection{2 $\mathrm{pH}$ calculation of copper precipitation}

In the lean solution, $\mathrm{Cu}(\mathrm{CN})_{4}{ }^{3-}$ is the main copper, and the complexation stability constant is $5.0 \times 10^{-28}$ as shown in Table 1, the concentration of cyanogen ion is $3.04 \times 10^{-6} \mathrm{~mol} \cdot \mathrm{L}^{-1}$. The weak acid dissociation constant of hydrogen cyanide is $6.2 \times 10^{-10}$, it can be concluded that when the $\mathrm{pH}$ value in the solution is less than 3.69 , the dissociation reaction of $\mathrm{Cu}(\mathrm{CN})_{4}{ }^{3-}$ is carried out to the right to generate hydrogen cyanide gas and the black $\mathrm{Cu}_{2} \mathrm{~S}$ precipitation.

The reaction of copper cyanide complex in acid system is calculated as follows:

$$
\mathrm{Cu}(\mathrm{CN})_{4}{ }^{3-} \rightleftharpoons \mathrm{Cu}^{+}+4 \mathrm{CN}^{-} \quad \mathrm{K}_{\mathrm{d}}=5.0 \times 10^{-28}
$$

In the solution of $0.13 \mathrm{~mol} \cdot \mathrm{L}-1$, it can be seen from the calculation that:

$$
\begin{gathered}
\mathrm{C}\left(\mathrm{Cu}^{+}\right)=7.60 \times 10^{-7} \mathrm{~mol} \cdot \mathrm{L}^{-1} \\
\mathrm{C}\left(\mathrm{CN}^{-}\right)=3.04 \times 10^{-6} \mathrm{~mol} \cdot \mathrm{L}^{-1} \\
\mathrm{HCN} \rightleftharpoons \mathrm{H}^{+}+\mathrm{CN}^{-} \quad \mathrm{K}_{\mathrm{a}}=6.2 \times 10^{-10}
\end{gathered}
$$

When $\mathrm{C}\left(\mathrm{H}^{+}\right) \cdot \mathrm{C}\left(\mathrm{CN}^{-}\right)=\mathrm{K}_{\mathrm{a}}, \mathrm{HCN}$ gas began to overflow from the solution, and the dissociation of copper cyanide complex proceeded to the right, and $\mathrm{Cu}^{+}$ gradually increased in the solution. From this we can calculate $\mathrm{C}\left(\mathrm{H}^{+}\right)=2.04 \times 10^{-4}$, the $\mathrm{pH}$ is 3.69 .

\section{Test}

\subsection{Test Sample}

The sample used in this test is the lean solution produced by the leaching of high copper concentrate from a smelting company. The test results of main components in the sample are shown in Table 2.

Table 2 Composition of test sample

\begin{tabular}{ccccccc}
\hline Unit & $\mathrm{Cu}$ & $\mathrm{Zn}$ & $\mathrm{Pb}$ & $\mathrm{SCN}^{-}$ & $\mathrm{SO}_{4}{ }^{2-}$ & $\mathrm{CN}^{-}$ \\
\hline $\mathrm{g} / \mathrm{L}$ & 8.22 & 0.55 & 0.01 & 26.98 & 40.42 & 3.90 \\
$\mathrm{~mol} / \mathrm{L}$ & 0.13 & 0.008 & Trace & 0.47 & 0.42 & 0.15 \\
\hline
\end{tabular}

It can be seen from table 2 that the content of copper and zinc is $8.22 \mathrm{~g} / \mathrm{L}$ and $0.55 \mathrm{~g} / \mathrm{L}$ respectively.

\subsection{Test equipments and reagents}

$\mathrm{Na}_{2} \mathrm{~S} \cdot 9 \mathrm{H}_{2} \mathrm{O}$, Three head reactor, Magnetic stirrer, Measuring cylinder, Concentrated sulfuric acid, Sodium hydroxide, Vacuum filter, Gas washing cylinder, The $\mathrm{pH}$ meter, Stopwatch, Constant pressure liquid funnel.

\subsection{Test process}

Zinc precipitation process: take a certain amount of lean liquid to be added to the reaction kettle placed on the magnetic stirrer, turn on the magnetic stirrer to make the rotor drive the lean liquid to rotate, insert the $\mathrm{pH}$ meter into the lean liquid, and slowly add sulfuric acid into the lean solution with a constant pressure separating funnel until the required $\mathrm{pH}$ value is reached, $\mathrm{Na}_{2} \mathrm{~S} \cdot 9 \mathrm{H}_{2} \mathrm{O}$ is added, and the stopwatch is used to timing. After the reaction reaches the predetermined time, turn off the magnetic stirrer.

The liquid after reaction is separated by vacuum suction filter, and the liquid is retained for subsequent copper precipitation.

Copper precipitation process: add the filtered liquid in the zinc precipitation stage into the reactor placed on the magnetic stirrer, slowly add sulfuric acid into the lean solution with constant pressure separating funnel until the required $\mathrm{pH}$ value is reached, add $\mathrm{Na}_{2} \mathrm{~S} \cdot 9 \mathrm{H}_{2} \mathrm{O}$, use 
stopwatch to timing, and turn off the magnetic stirrer after the reaction reaches the predetermined time. The liquid after reaction is separated by vacuum suction filter.

The theoretical amount of sodium sulfide in the test is calculated according to formula 2) and formula 3 ).

\subsubsection{The $\mathrm{pH}$ test}

Under the condition that the amount of sodium sulfide is 1.2 times of the theoretical calculation amount and the reaction time is $5 \mathrm{~min}$, the test is carried out under different $\mathrm{pH}$ values. The test results are shown in Figure 1.

\subsection{Zinc precipitation test}

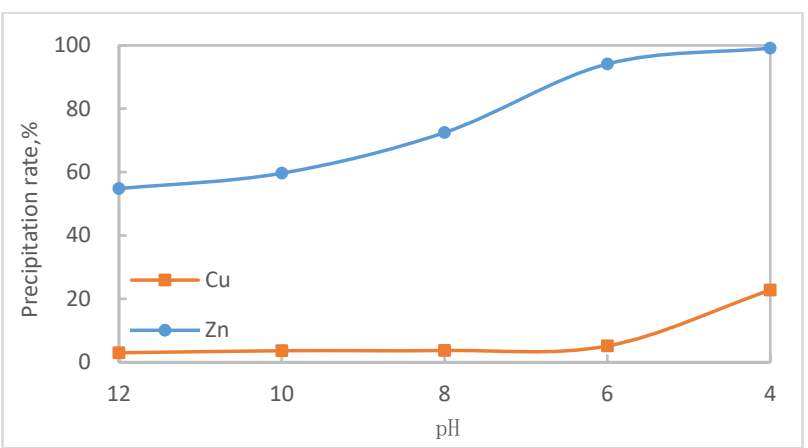

Fig. 1 Changes of zinc precipitation rate under different $\mathrm{pH}$ values

It can be seen from Figure 1 that the change of $\mathrm{pH}$ value has a great influence on the precipitation rate of metal ions. When the $\mathrm{pH}$ value is less than 8.0, the precipitation rate of zinc increases rapidly. When the $\mathrm{pH}$ value is 6.0 , the precipitation rate of zinc reaches $94.13 \%$, and the precipitation rate of copper is low; When the $\mathrm{pH}$ value is less than 6.0 , the copper in the liquid begins to precipitate. In order to ensure the separation effect of copper and zinc in lean solution, the $\mathrm{pH}$ value of zinc precipitation test was determined to be 6.0 .

\subsection{Copper precipitation test}

\subsubsection{The $\mathrm{pH}$ test}

In the copper precipitation stage, sodium sulfide 1.2 times of the theoretical calculation amount was added, and the test was carried out under the condition of reaction time of $5 \mathrm{~min}$. The test results are shown in Fig.3.

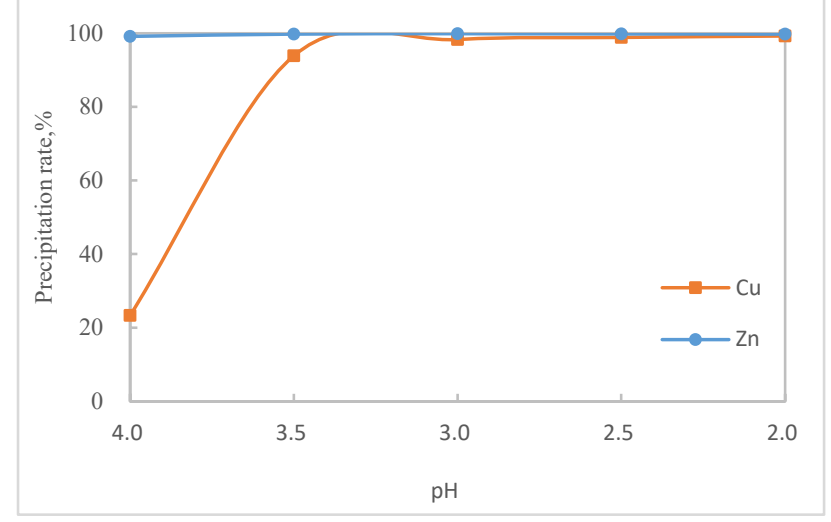

Fig. 2 Changes of copper precipitation rate under different $\mathrm{pH}$ values

It can be seen from Figure 3 that when the $\mathrm{pH}$ value is less than 4.0, the copper precipitation rate increases obviously. Considering that with the gradual decrease of $\mathrm{pH}$ value, a large amount of sulfate will be introduced into the pulp, it is determined that when the $\mathrm{pH}$ value is 3.0, the copper precipitation rate reaches $98.30 \%$, and the zinc precipitation rate reaches $99.76 \%$.

\subsection{Product inspection}

The three elements of copper, zinc and iron in the precipitation products were analyzed. The analysis results are shown in Table 3.
Table 3 Inspection list of precipitated products

\begin{tabular}{|c|c|c|c|}
\hline Name & Moisture content,\% & $\mathrm{Cu}, \%$ & $\mathrm{Zn}, \%$ \\
\hline Zinc product & 60.85 & 2.04 & 42.97 \\
\hline Copper product & 58.63 & 58.33 & 1.58 \\
\hline
\end{tabular}

According to table 3, the moisture content of zinc products and copper products is $60.85 \%$ and $58.63 \%$ respectively after filtration. The zinc grade of zinc products is $42.97 \%$, and copper grade is $2.04 \%$. The copper grade of copper products is $58.33 \%$, and zinc grade is $1.58 \%$. 
Copper in zinc products is mainly due to the high local $\mathrm{H}^{+}$concentration in the process of zinc precipitation and $\mathrm{H}_{2} \mathrm{SO}_{4}$, which can not be dissolved back to $\mathrm{Cu}_{2} \mathrm{~S}$ precipitation. The reason for zinc content in copper products is that the laboratory can not filter zinc precipitation thoroughly, and a small amount of zinc precipitates enter into the copper precipitation process.

\section{Conclusion}

(1) Through theoretical analysis, the $\mathrm{pH}$ value of zinc precipitation in lean solution of a smelting company is 5.99 , and that of copper precipitation is 3.69 .

(2) In the experiment, the $\mathrm{pH}$ value of zinc precipitation is 6.0 , and the zinc precipitation rate is $94.13 \%$; the $\mathrm{pH}$ value of copper precipitation is 3.0 , and the copper precipitation rate is $98.30 \%$. The zinc content in zinc products is $42.97 \%$, and the copper content in copper products is $58.33 \%$.

(3) This process realizes the separation of copper and zinc products in the lean solution, reduces the metal content in the lean solution, and increases the economic benefits of the enterprise.

\section{Reference}

1. Deng Tong. Treatment of cyanide gold extraction wastewater. Gold science and technology, 4:33-35(1995).

2. Gao Daming. Looking back on the treatment technique of cyanide-bearing waste water in the past 20 years. Gold, 21:46 -49(2002).

3. Liu Yali, Cao Huilan. Comprehensive treatment of cyanide wastewater from gold concentrate. Shaanxi Environment, 10:14-16(2003).

4. Lan Xinzhe, Zhang Conghui. Development of cyanide recovery and recycling technology from gold leaching tailings. Gold science and technology, 7:40-45(1997).

5. Department of inorganic chemistry, Dalian Institute of Technology. Inorganic chemistry. (People's Education Press, Beijing,2013).

6. Lu Yiyuan. Precious metals metallurgy. (Zhongnan University of Technology Press, Changsha,1994.) 